\title{
¿Quién fue Marie Langer?
}

\author{
Entrevista pública a Nancy Caro Hollander y a Juan Carlos Volnovich \\ Sergio Garcia de la Cruz para \\ Barquitos Pintados. Experiencia Rosario \\ Facultad de Psicología U.N.R. \\ 24-06-2017
}

Silvia Grande: Bueno, en principio darles la bienvenida y agradecerles a todos su presencia y agradecer fundamentalmente a Claudio Cúneo porque sin su trabajo organizativo esto no hubiera sido posible y todos saben que es una tarea difícil la de organizarnos a nosotros!!!

Agradecer también al Comité Organizador de la revista que puso idea, discutió, impulsó todo este trabajo.

A Sergio García de la Cruz que apenas lo convocamos aceptó entusiasta la propuesta, colaboró en darle forma y ponerla a funcionar.

A Nancy Hollander y Juan Carlos Volnovich, a ambos les queremos agradecer su generosidad y la disposición "absolutamente interesada" que tienen en esto; dos atributos que me parecen fundamentales. La generosidad de nuestros invitados constituye realmente una actitud a remarcar sobre todo en épocas donde con la escasez de ideas florecen los autoritarismos y desde los contextos institucionales se produce el empobrecimiento que va llevando casi una ausencia de ámbitos de discusión, promoviendo actitudes mezquinas. Nosotros teníamos pedida y reservada una de las aulas que está con manteles y flores en la parte de delante de la facultad, pero nos mandaron al espacio de fondo, el más viejo de toda la facultad: ¿será que nosotros hablamos de cosas viejas, de cosas que no son muy "modernas", de cosas que no se usan más? ¿Será, entonces, que algo de la pobreza nos queda para nosotros?

No es la primera vez que nos ocurre y seguramente seguirá ocurriendo, pero nunca deja de sorprendernos la mezquindad y la necedad, aunque no somos inocentes, esto lo vamos a decir, no somos "víctimas de" y algo haremos e intentamos seguir haciendo...

Bueno, les decía de la generosidad de quienes ofrecen su producción, la comparten y también de la disposición interesada en transmitir una historia para que siga viva en las discusiones que promueve. Esta es una posición ética que nos conmueve. Digo, la generosidad y la disposición interesada no son valoraciones morales, son posiciones éticas de nuestros invitados. Esta disposición que lo llevó a Juan Carlos a regalarme hace unos años un CD con una entrevista a Marie Langer de una colega americana y me dijo: "A vos te va a interesar". Yo lo miré como diciendo: “¿Qué hacemos con esto?”... Y él me dijo, en ese momento: "Hagan con ella”.

Yo entendí que nos daba libertad para distribuirla, difundirla, para poder hacerla pública. Después entendí que se trataba de otra cosa. Que era una apuesta, que nos estaba desafiando a "hacer con ella". Hacer con Marie Langer. Qué desafío!!! Marie Langer es una especie de símbolo de posiciones, construcciones, exilios y nuevas construcciones; de una voluntad de hacerse dueña de su destino. Toda una posición: hagan con ella, no "hagan como ella". Sino sigan las huellas, las huellas de sus preguntas. Ya Fernando Ulloa nos había indicado que de eso se trata- 
ba... pero como suele ocurrir, aquí descubrimos lo que debíamos estar sabiendo.

¿Qué huellas? Las de las preguntas que ella fue instalando: la pregunta acerca del lugar de la mujer en la teorización psicoanalítica, de la tensión política-psicoanálisis y psicoanálisismarxismo, del síntoma individual, de lo social, de lo social en el síntoma y del síntoma social. Las preguntas que nos retornan, prevalentemente acerca "del mundo de afuera" de nuestras instituciones psicoanalíticas. Marie Langer decía que en la APA "le tenían fobia”a ese mundo de afuera. Entonces, retomar estas preguntas es un modo de HACER CON ELLA.

Para nosotros hoy es una apuesta este proyecto de publicación. Estamos comenzando en este año el cursado de la octava cohorte con cincuenta cursantes, volviendo a apostar a construir una práctica que haga de nuestro hacer en los espacios de lo público una dimensión de análisis de nuestro saber. Que el saber no se constituya en una justificación que elida lo molesto de la realidad, una construcción que nos protege "fóbicamente" para acallar lo que ruidosamente nos molesta porque no encaja con la teoría. Hace mucho que decimos, las teorías hacen institución. No nos proponemos pensar lo social desde el psicoanálisis, sino pensar el psicoanálisis desde la práctica con la numerosidad social. (Ulloa, 1995). Marca de Fernando Ulloa.

Por último: la publicación, "Barquitos Pintados". Publicación anhelada desde mucho tiempo pero siempre postergada. Siempre nos aparece alguna urgencia que nos distrae y ponernos a escribir es algo que siempre postergamos.

La carrera tiene ya más de 100 egresados, la mayoría de ellos transitan lugares muy incómodos en espacios institucionales: trabajan en centros de salud, en hospitales generales, en hospitales monovalentes, en escuelas, en centros barriales, en centros de día. Con mucha potencia de trabajo pero con una debilidad a la hora de producir marcas (para poder releerlas), escrituras que nos permitan hacer de esas prácticas algo más que el relato de una experiencia más, escrituras que logren inscribirse en una experiencia colectiva. Que cada experiencia no sea una especie de "empezar de nuevo", en soledad. Esta sensación que tenemos siempre en las instituciones de que estamos solos, de que estamos siempre empezando de nuevo.

Juan Carlos en 2007, cuando nos relataba su experiencia en Nicaragua, nos dijo algo que por su efecto fue una verdadera intervención. No sé si él se enteró del efecto que nos produjo a todos nosotros. Cuando le preguntamos cómo había hecho para trabajar en Nicaragua, en esas condiciones y totalmente solo, él responde sonrientemente: "no estaba solo", aludiendo a los colectivos que transitó. Entonces, ahí aprendimos, a partir de esa intervención, que no estamos solos si logramos hacer de nuestras prácticas, experiencias para compartir y repensar, si nuestra experiencia se inscribe, se configura como un colectivo, como un proyecto.

Entonces, gracias a la generosidad y la disposición "completamente interesada" de Juan Carlos y Nancy, vamos a abrir ahora un capítulo de nuestra revista: es decir, ya estamos en la revista para escribirla juntos. Damos lugar ahora a éste diálogo abierto que va a formar parte de esta primera comunicación. Nuestra idea es precisamente que en este momento esta entrevista se constituya como un disparador para un diálogo abierto en el que participemos todos de la escritura.

Pensamos que de este modo, efectivamente, se puede concretar esta apuesta a la conformación de colectivos de pensamiento. Parece que somos muchos los escritores interesados de escribir e inscribirnos en esta historia. Gracias.

\section{(Aplausos)}

Juan Carlos Volnovich: La verdad, estoy muy feliz de compartir con ustedes esta mañana, tener el honor de estar acá. 
Para seguir un poco lo que decía Silvia, celebro la iniciativa de Silvia y agradezco muchísimo esta convocatoria. Agradezco muchísimo a Claudio que se encargó de las traducciones y los mensajes.

Bueno, había tomado para juntarnos algo referido a Marie Langer que tiene la condición de juntarnos con nuestra historia: Marie Langer fue la única mujer del grupo de los cinco fundadores de la Asociación Psicoanalítica Argentina, de los que fundaron el psicoanálisis en Argentina. Y es tal vez una de las figuras más olvidadas, más borradas de la historia. Generaciones y generaciones de psicólogos y de psicoanalistas no tienen la menor idea de quién fue esta mujer que además en su posición tiene una vigencia enorme. Y si nosotros no contamos con nuestra historia estamos fritos.

Entonces lo fundamental me parece que es recuperar nuestra historia y también soldar las fracturas en la memoria que las dictaduras militares y el capitalismo intentaron consolidar.

Nancy Hollander es... es muchas cosas. Pero fundamentalmente es historiadora. Ella se dedica a la historia y es profesora emérita en una universidad de California, en Los Ángeles. Y además, es psicoanalista. Es miembro del Instituto Psicoanalítico de San Francisco y pertenece a la IPA.

Pero además es una activista, es una militante. Si yo me pusiera a contarles a ustedes todas las actividades militantes de Nancy, todas las travesuras de Nancy... Sería la una y todavía hablaríamos de eso.

Pero sí me gustaría que sepan que ella está involucrada en varios grupos activistas y militantes de resistencia desde varios lugares. Desde sectores dentro del Partido Demócrata que apoyaron a Bernie Sanders, un líder socialista, hasta otros grupos con quien también están tratando de hacer una política de oposición a Trump. Pero esto no empezó ahora, ya antes en el 2011 cuando hubo un movimiento importante que también contó con su colaboración y fue Occupy Wall Street, es decir una toma del Wall Street que se hizo en parte como secuela de lo que fue el 15 de marzo en España. Ese marzo del 2011 que luego en septiembre, en Estados Unidos se transformó en multitudes que ocuparon distintos lugares como Wall Street y en otras ciudades del país como manera de oponerse fundamentalmente a la política y a la economía neoliberal.

Nancy, además, pertenece a un grupo que está trabajando en apoyo a los palestinos: es un grupo de psicoanalistas israelíes, psicoanalistas judíos norteamericanos, psicoanalista palestinos y psicoanalistas árabes que trabajan juntos en varios países para... no digamos ayudar, sino también entender y colaborar, lo cual es un análisis mucho más complejo porque es encontrarse desde el psicoanálisis para comprender lo que es la situación de los palestinos. Y yendo para atrás, estuvo en los grupos que estaban luchando contra la Guerra de Vietnam.

Pero a veces lo importante es el comienzo, en este caso el comienzo de la historia latinoamericana de Nancy. En el año ‘69 ganó una beca en Estados Unidos para venir a Argentina a estudiar algo que no tiene posibilidades de ser estudiado: el peronismo. (Risas)

El gran desafío de Nancy fue llegar en el año '69 con un interrogante académico: "¿qué es el peronismo?”. En realidad, logró enamorarse de un peronismo y compartió toda esa experiencia nuestra del 1969 al 1974: es decir, vivió años muy significativos para Argentina. Y a partir de ahí, vivió todo este interés por lo que es la política de América Latina.

Poco después, en el año '74 -esto es muy curioso porque es una coincidencia, de esas increíbles- justo en la misma época que Marie Langer, Nancy también se fue al exilio porque salió de Argentina para ir a México.

Y es ahí donde Nancy conoció a Marie, y es ahí donde comenzó no sólo una amistad sino 
un trabajo conjunto casi diría de investigación donde estuvo muy ligada con todos los afectos de la implicación personal de cada una de ellas con la política y con lo social.

Entonces para mí es un honor darle la palabra a Nancy.

(Aplausos)

Nancy Caro Hollander: Bueno, gracias Juan Carlos.

Quisiera agradecer mucho a Silvia Grande y Claudio Cúneo por haber armado esta reunión.

Lo primero que quisiera decirles es que mirando desde acá hacia ustedes me hace recordar a la primera vez que hable con Marie Langer personalmente: estábamos en la Universidad de Berkeley (California), yo estaba donde están ustedes y ella estaba sentada en el escenario hablándonos. Vestía un jean y una camisa del estilo campesino centroamericano, muy informal, y empezó a hablar. Estaba, en ese momento, buscando juntar fondos para el trabajo en Nicaragua del que luego hablaremos.

Es muy impactante porque sólo la conocía por su libro y les cuento cómo: en aquel entonces, como dice Juan Carlos, tenía que irme de Argentina por muchas razones. En el año '74 tenía amigos que ya habían sido desaparecidos antes de la dictadura, algunos sufrieron las torturas. Estando en Estados Unidos sentía la alienación porque ya conocía lo que estaba sucediendo en Argentina. Un día vino un sociólogo argentino que se encontraba exiliado en México a presentar sus trabajos en la Universidad y me pidieron que me encargara de la traducción para él. Después de pasar un fin de semana juntos hablando, charlando me preguntó: "pero, decime una cosa, ¿no conoces a Marie Langer?!”. Le dije que no, que no la conocía: “¿quién será?”, me preguntaba. "Pero ustedes coinciden tanto en las perspectivas, ¡las dos son marxistas, las dos son feministas!" me dijo y si bien en ese momento yo aún no era psicoanalista, conocía bastante por la ruta del feminismo. Entonces me prometió que me mandaría un libro que ella escribió con dos periodistas mexicanos.

Luego él regresó y sí, me mandó el libro. Lo leí, y quedé fascinada. ¡Y me pareció un crimen que no la conociera nadie! Ni allá en Estados Unidos, ni en Europa.

Esta mujer fantástica cuya vida combina con los tres pensamientos más importantes del siglo XX: marxismo, feminismo, psicoanálisis.

En ese momento, decidí que quería escribir su biografía. Entonces, le escribí una carta muy formal: "Estimada Doctora Langer. No me conoce, pero..." y le dije que luego de escribirle, dos semanas después, la llamaría.

Así fue, la llamé y ella contestó, en su español con acento austriaco muy fuerte: "Pero, iquerida! ¿No te acordás que nos conocimos cuando estuviste en México presentando el documental que hiciste sobre el movimiento peronista, los montoneros y el exilio?”. Finalmente, ¡ella me conocía a mí, como yo la conocía a ella!

Se mostró muy interesada a mi propuesta y nos conocimos en Berkley (California) y de ahí empezaron los años de amistad y de trabajo juntas.

Esto me conmueve mucho porque yo estuve en el lugar de ustedes mientras ella se encontraba acá (en el escenario), y luego llegué a conocerla.

Sergio: En principio quería agradecerle profundamente a Silvia Grande, a Iris Valles y a Claudio Cúneo que me invitaron a hacer parte de este evento. Silvia decía que yo rápidamente había aceptado...porque para mí estar convocado aquí con Nancy, Juan Carlos, realmente me resulta muy grato y muy interesante. Yo hace un tiempo estoy trabajando algunas cuestiones de los escritos de Marie Langer. Estoy haciendo un trabajo de tesis doctoral. La historia de ella y algunas cuestiones de su recorrido me resultan habituales porque es algo que estoy recorrien- 
do. Acuerdo con lo que decía Juan Carlos, es un personaje en la historia, particularmente en la historia del psicoanálisis argentino, que está olvidado. Al menos en la formación de grado, sus teorizaciones, sus prácticas no aparecen. Me parece que es muy interesante rescatar la historia de esta fundadora y hacerla trabajar. Aún así, si bien no ha estado visibilizada...uno se encuentra con cierta construcción de dispositivos, uno ahí advierte que ahí está la huella de pensadores como Langer que han transmitido a distintas generaciones, aún invisibilizando su nombre, cierto modo de pensar una práctica. No? A mí me interesa mucho el modo en que ella fue pensando la práctica del psicoanálisis. En ese sentido me parece un momento muy grato, había pensado el recorrido por algunas preguntas puntuales para dialogar con Nancy. A Juan Carlos lo conozco de haberlo leído, de haberlo escuchado, tengo una transferencia y una profunda admiración. A Nancy no la conocía hasta que en estos días leí este libro que se llama "Amor en los tiempos del odio" y se los recomiendo. Es un libro conmovedor y al mismo tiempo es tremendo, muy doloroso. Me produjo mucho dolor y mucho interés, realiza un rescate de ciertas prácticas militantes del psicoanálisis y entre ellas la de Juan Carlos y la de Mimí Langer. Así que estoy muy agradecido.

Hay tres puntos claros en la producción y en la vida de Marie Langer: la institucionalización del psicoanálisis, las preocupaciones sobre la femeneidad - la cuestión del feminismo es una problemática que se va encontrando en sus intereses desde muy temprano en sus teorización, fundamentalmente en sus interrogantes sobre problemáticas femeninas-, el tercer punto es un tema que aparece explícitamente más tardío en su vida, el psicoanálisis y la política. Digo explícitamente porque hay algunos autores que han secuenciado la historia de Langer y ubican tres momentos: el momento de su juventud, un momento intermedio que es para mí uno de los momentos más ricos de ella, que tiene que ver con todo el recorrido que hace en la década del cuarenta, del cincuenta y parte del sesenta donde produce sus grande producciones teóricas sobre la femineidad y algunas cuestiones sobre psicosomáticas. Después que rompe con la APA, aparece lo que se denomina el período militante. Y pensaba en un rasgo que puede identificar a esta mujer, Langer es una mujer de acción. Acción entendida en términos de la praxis marxista, sus producciones en la década del cuarenta y del cincuenta están repletas de historias clínicas, hace un trabajo permanente sobre la práctica del analista, tomando los conceptos y pensando cómo se ponen en juego, que efectos tienen, que efectos producen y eso me parece muy interesante. Después por algunas cuestiones que sería lindo discutir, abrir...tomando el libro que te impacto a vos Nancy: "Memoria, Historia y Diálogo Psicoanalítico", un libro autobiográfico pero que en realidad lo piensa en términos de la historia, de construir una memoria en relación a un diálogo con otros. Me parece que es algo de esto lo que a mí me ha legado Marie Langer que no tiene relación con un recorrido personal, que indudablemente siempre esta, pero es la apuesta a que la producción personal se ponga en juego o se transforme en la relación con otros. Bueno, eso un poco para contextualizar lo que a mí me impacto de Marie Langer.

Una de las primeras preguntas que le hacía, es que a mí me parece interesante poder pensar la relación entre historias tan disímiles, vos que venís de EE.UU, ella que venía del centro de Europa, cómo fue no solamente el encuentro concreto sino que te fue despertando el encuentro con ella, que fibras de tu propia tu historia, en el recorrido con ella te fue cautivando... Por lo que yo leí en el libro te ha generado muchas movilizaciones en tu vida. Si querés contarnos un poco de esto...

Nancy: Si, te entiendo bien, como dijo Juan Carlos, mi formación tiene que ver con ser estudiante en la universidad durante la guerra en Vietnam y durante la lucha para los derechos 
civiles de los negros. Y después el movimiento que surgió de eso que allá se llama el movimiento de liberación de la mujer. Y yo en medio de todo esto en mi ciudad, creo que la fuente original era mi experiencia creciendo como judía en un ambiente, un pueblito en California, donde no hubo muchos otros judíos y porque yo sentía como "el otro". Una persona diferente que yo tenía que esconder un poco que era judía. No sé de dónde aprendí eso pero lo sabía. Entonces creo que eso fue formándome como identificada con el otro. Y después una militancia como no parte de la cultura dominante. Empecé a estudiar la historia de América Latina, ya me había formado como marxista y vine a la Argentina sintiendo que iba a participar en la historia activamente. Porque eran unos momentos muy interesantes, yo quería participar de su democracia, su ex dictadura, después el retorno de Perón, después Cámpora y la historia. Después la represión de eso. Muy metida en eso. Después cuando tenía que irme y regresar a EE.UU ya había pasado un poco los movimientos sociales. Yo sentía mucha alienación...después surgió Reagan, las guerras en América Central, empecé a militar en esos movimientos de trabajadores de salud mental sobre las realidades de las luchas en América Central. Entonces estaba en eso cuando me presentó ese sociólogo argentino el libro de Mimí Langer. Y es cierto que mi formación y la formación de ella estando en otro continente, en Europa, creció entre las dos guerras mundiales en la vieja Europa cuando la democracia social permitía una cultura muy abierta, muy interesante donde se cuestionaba todo del capitalismo y la opresión de clase, la opresión de la mujer y el psicoanálisis todo junto en ese ambiente en que se formó ella como chica. Más lo que pasaba en su casa, que se identificaba mucho con las preocupaciones de su papá, con la revolución rusa, leyó algunos libros de feministas rusas identificadas con la revolución socialista por la lucha por la igualdad de la mujer. Entonces ella, con algunos patrones de desidentidad con su mamá, el tipo de vida burguesa que llevó su mamá, ella crecía y cocinaba en un ambiente que le iba a permitir desarrollar otra manera de pensar, de cuestionar. Y ella también en los 30 empezó a darse cuenta que estaba pasando algo muy feo, que el fascismo se estaba comiendo a la democracia social. Y empezó a pensar que solamente el socialismo podía combatir al nazismo y además ocuparse de la lucha para la igualdad sexual. Entonces empezó a militar con el partido comunista. Y también empezó, por ser judía, una vez recibida de la facultad de medicina no podía hacer una práctica en los hospitales... entonces eso y otras cosas, la dirigieron hacia el psicoanálisis. Y entró a estudiar y analizarse en el instituto de Freud. Empezó a analizarse y militar en el movimiento del partido comunista clandestinamente porque toda actividad política en contra del fascismo ya era ilegal. Entonces era como un estrés... analizándose dijo que de joven se sentía con mucha culpa pasando tiempo analizando su ombligo mientras estaba en juego la sociedad. En ese momento, para entender, el instituto se había definido como neutral diciendo que el psicoanálisis es una actividad científica neutral. No tiene nada que ver con lo social. Entonces, una persona como miembro o candidato no podía estar militando o ser activista político. Entonces era una contradicción total porque el analista tenía que dejar de analizar a la gente activista o los activistas candidatos no podían hablar nada de su activismo en sus análisis. ¿Y cómo se puede practicar la asociación libre si tiene que estar siempre pensando "no debo decir esto, no debo decir esto"? Eso me imagino que paso también mucho en la dictadura acá. Bueno, ella no podía más. Le parecía una violación del fin del psicoanálisis (...) Entonces ella le ordenó a su futuro marido, que estaba en España durante la guerra civil, dejarla ayudar a los soldados republicanos. Con todas las experiencias, más sufrir personalmente dos o tres experiencias de estar embarazada y perder. Nació una vez una nena que vivió pocos días y, por falta de atención médica, de incubadora, falleció. Tuvo dos o tres traumas así, con todo eso y 
finalmente con la caída de España, ellos huyeron de Europa en llamas hacia América Latina. Llegaron a Uruguay, por un tiempo, muy pobres. Ella empezó a reencontrarse con el marxismo y el psicoanálisis. Se trasladan a Buenos Aires y, muy poco después, ellos fueron los fundadores de APA. Ella dice que otra gente inmigrante de Europa, llegando durante y después de la guerra con el gobierno de Perón ,un populismo que para la clase media identificada con Europa parecía un tipo de fascismo del nuevo mundo, no confía en exponerse mucho en el ámbito político. Entonces la militancia se ocupó de crear un instituto psicoanalítico muy importante. Entonces ella le dedicaba este momento de su vida, alrededor de los 50 y 60, en crear un ambiente psicoanalítico que no solamente podía tener mucho éxito profesionalmente sino también influir en la cultura popular. Cosa que se hizo, ustedes deben saber algo de esa historia. No sé... La primera generación de psicoanalistas se dedicaba a enseñar en la universidad, dar charlas en la radio, escribían artículos en los diarios, vender la revista de psicoanálisis argentino en kioscos y librerías. Realmente profundizaba en la cultura.

Juan Carlos: Quisiera aclarar algo del contexto de la época. En ese momento fundacional, cuando se funda el psicoanálisis, donde para fundar una asociación hacía falta gente que estuviera analizada. Y los únicos que tenían análisis previos eran Mimí, que se había analizado con Richard Sterba en Viena, Garma, que se había analizado con Theodor Reik, pero los demás, ni Racovsky ni Pichón Rivière se habían analizado. Que eran los otros que fundaron la APA. Me parece que lo fundamental, algo que hoy en día es inimaginable, es que el partido comunista argentino era muy poderoso y muy dogmático. Si eras psicoanalista no podías ser del partido comunista. Si uno era comunista, no podía ser psicoanalista. Es decir, que por un lado la asociación psicoanalítica no quería que quien se formara como psicoanalista estuviera en política. $\mathrm{Y}$, por otro lado, el partido comunista exigía que sean reflexólogos si querían dedicarse a la psicología. Y ella, tenía un pasado comunista y psicoanalítico. Y se dio un problema muy serio.

Nancy: Y fue en esa época de su vida que se puso a estudiar y desarrollar trastornos de la mujer en su vida reproductiva y también en las enfermedades psicosomáticas. Y escribió su libro "Maternidad y sexo" que realmente en esa época fue una cosa revolucionaria. Porque se notaba su capacidad de pensar independientemente. Y dentro del psicoanálisis en esa época fue un desastre para la mujer. Porque todo el mundo entre los intelectuales sociólogos, historiadores, psicólogos, psicoanalistas, por razones políticas y personales querían que saliera la nueva edición. Después de la otra edición en '72, yo creo que ella había prometido escribir más. Llegó a publicar la tercera edición sin que escribiera más porque ella ya estaba en otra cosa, ya empezando el '69 ya estaba mucho más interesada, mucho más metida en las luchas políticas dentro del Psicoanálisis tratando de fomentar el Psicoanálisis políticamente comprometido dentro y fuera, militando en movimientos de DDHH. Entonces dejó de lado tratar de enfocarse en escribir más sobre ese libro. Pero después publicó muchos trabajitos en los cuales se ve el cambio de su posición y el desarrollo de su pensamiento en cuanto a la mujer. Y ella fue integrando lo que aprendía en su contacto con los movimientos feministas. Yo recuerdo una cosa muy interesante que ella siempre mantenía, ella estaba de acuerdo con la necesidad de que la mujer tenga una militancia aparte, movimientos autónomos de la mujer. Porque sin eso, los movimientos progresistas, los movimientos izquierdistas, nunca iban a rendirse a la importancia de una lucha para la igualdad de género. Entonces un movimiento muy independiente era para ella muy importante. Pero ella aconsejaba a las feministas. Para ella lo que se veía en la necesidad de la mujer de estar militando aparte, solamente con otras mujeres, escondía el conflicto inconsciente. El conflicto no resuelto con la madre omnipotente, que fue desviado y proyectado hacia el hombre. Ella 
pensaba que cada mujer que estaba en el movimiento tenía que darse cuenta de eso y trabajarlo. Porque para ella un movimiento feminista aparte del movimiento para el socialismo, de la lucha para el socialismo, no nos iba a llevar a ningún lado. Porque no reconoce que la mujer nunca va a conseguir la igualdad en el capitalismo. El capitalismo basado en jerarquías de poder, por supuesto ligado al patriarcado y, bueno pues, opresión basada en clase, basada en raza, basado en etnias. En mi país también inmigrantes. Entonces para ella había una cosa que se heredó de su enfoque kleiniano y lo tomé muy en serio, yo pensé que tenía razón. Porque en la primera ola del feminismo, el Movimiento de Liberación de la Mujer, había un principio sobre el liderazgo, "ya estamos hartas del liderazgo y el control desde arriba", queríamos movimientos basados en la democracia. Pero resultó que se reprimía a la capacidad de muchas mujeres de realizarse con sus propias capacidades, sí, de ser líderes, de ser muy capaces de ayudar a las otras. Y había una ideología que reprimía todo eso. Eso es lo que notó Mimi Langer, y lo atribuyó a conflictos inconscientes. Eso fue para mí muy interesante.

Sergio: Dos cuestiones me quedaron en el tintero cuando te escuchaba. Una es una curiosidad, que cuando ella estaba en Uruguay, trabajando de cocinera, y se encuentra con un anarquista que le propone dar una conferencia sobre Psicoanálisis y Marxismo, ella dice "yo de Marxismo podría hablar pero de Psicoanálisis...". En realidad hizo una formación muy breve. Entonces el anarquista le da un libro de Osborn, que es un inglés que había escrito un libro breve sobre Psicoanálisis y Marxismo que no estaba ligado a la escuela de Frankfurt. Y a partir de ese libro ella da una conferencia que yo sospecho debe haber sido una de las primeras conferencias sobre Psicoanálisis y Marxismo que se deben haber dado en Latinoamérica; después retoma el diálogo entre psicoanálisis y marxismo. En relación a la concepción de la mujer hay un trabajo que hace Juan Carlos donde rescata este texto que escribe en "Cuestionamos I": La mujer: sus límites y potencialidades. Donde lo que toma es el concepto de invisible y liga el lugar de la mujer invisibilizada cruzándolo con el concepto de plusvalía de la teoría marxista. A partir de este concepto articula esto que ya había trabajado en el año '39, porque esta conferencia la da en el año '39. Y después te quería preguntar, yo pensaba que era muy interesante trabajar esta autora por la vigencia que tienen sus escritos, inclusive sus escritos tempranos. Ella en "Maternidad y sexo" hace una referencia al aborto, quería traerte una cita y preguntarte que cosas pensabas vos, que cosas has hablado ella en relación a un tema que sigue teniendo una vigencia conflictiva o problemática en la sociedad. Ella dice en el '51 que "El aborto produce un claro trauma psicológico en la mujer. La mujer consciente o inconscientemente ha fantaseado durante toda su vida anterior con un hijo que algún día sería el de ella. Basta para ella enterarse de su embarazo, para que surjan estas fantasías y se liguen como promesas a lo que lleve dentro de sí. Se considera una criminal porque, en su inconsciente, no destruye con el raspaje el óvulo fecundado pocos días antes, sino asesina el niño, centro de todas sus fantasías maternales. Buscará y encontrará siempre el medio de castigarse a sí misma y a su compañero como un cómplice impune del crimen. Y si tienen hijos, éstos percibirán consciente o inconscientemente con horror el raspaje que su madre se practique. Se sentirá bruja y asesina, preguntándose gracias a qué suerte extraña ellos pudieron salvar su vida y nacer. Y se sentirán culpables ya que ella, al eliminar al hermano celado, ejecuta las fantasías criminosas de sus hijos". Yo quería preguntar, porque esta fue una apreciación muy temprana de ella, he leído que ha tenido después otras posiciones, pero quería saber si han hablado sobre esta problemática.

Nancy: eh...es muy complicado eso, porque sí estaba en su posición política a favor del derecho de la mujer de controlar su propio cuerpo. Ella también estaba al tanto de la ideología 
del patriarcado y de las fuentes de la necesidad por parte del hombre de controlar el cuerpo de la mujer. Y además de saber, como acabas de leer, la parte inconsciente de la mujer en cuanto a su capacidad de reproducir, las fantasías inconscientes...Me llaman la atención cuando ella habla de la fantasía de los chicos, de los otros hijos. Eso requiere que: o saben que su mamá abortó, o pescan inconscientemente que en la madre o en los padres algo había pasado, o que ellos inconscientemente transmiten a los hijos. Yo creo que, bueno, hablando de cómo después ella siguió pensando, lo que sí puedo decir es que ella y yo hablamos de una problemática que las dos notamos. Y yo creo que sigue siendo un problema. El movimiento feminista, para lograr el derecho de controlar nuestros cuerpos, teníamos que luchar y reivindicar el derecho de eso. Y luchar con el patriarcado para que nos deje la posibilidad de decidir por nosotras mismas. Y si queremos abortar, que lo hagamos con ayuda del médico y en ambiente seguro y sano, etc. Yo creo que el problema fue que había que negar los conflictos, la pérdida y el duelo. Como con cada decisión que tomamos, no tomamos otras decisiones, lo que sea, y siempre habrá pérdidas. Cuando nace un chico, si es hombrecito perdimos la mujercita. Y hay un momento, yo creo, que cada uno experimenta una pérdida, de lo que uno no tiene, al lado de la alegría de lo que uno tiene. Los hombres lo experimentan cuando eligen a una mujer para casarse porque pierden a todas las otras mujeres, o no las pierden, no sé (risas). Pero yo creo que tanto ella como yo notamos que es muy importante que la mujer que elige el aborto, se da cuenta que conmueve, que algo le pasa importante, o son las fantasías inconscientes que ella menciona en una época más temprana, o como ella empezó a pensarlo, una pérdida que una tiene que reconocer requiere un duelo, un reconocimiento de que algo importante pasó. No solamente que "Ah, bueno ya está", no es "ya está", tiene efecto. Yo no sé si es una contestación a tu pregunta pero...

Sergio: Bueno, avanzando un poquito en relación a otro eje que me parece que ha sido decisivo en su vida, que tiene que ver con el Psicoanálisis y la política...

Juan Carlos: Perdón, pero quería decir algo que son conflictos al interior mismo del feminismo, con respecto al por qué de la consigna; en los sectores más progresistas del feminismo dicen que las mujeres tienen derecho a decidir sobre sus propios cuerpos, y entonces los sectores más progresistas están muy de acuerdo. Pero entonces, los sectores más reaccionarios que están a favor de la prostitución consentida dicen que si las mujeres tienen derecho a decidir sobre sus propios cuerpos, y las mujeres deciden ser prostitutas, entonces no se puede hacer una ley que sirva para unas y no para otras. Entonces este es un conflicto actual importante y con respecto a este asunto de si las mujeres tienen derecho a decidir sobre sus propios cuerpos para abortar cuando quieran, en buenas condiciones y para ejercer la prostitución, cuando quieran, y en buenas condiciones (risas).

Nancy: Otra cosa que quería agregar, me imagino que no saben acá. En el último año, en mí país, desde que asumió la derecha, la ultra derecha, en muchos estados ahora están criminalizando el aborto. Había casos, por ejemplo, una mujer que está embarazada, cae y aborta espontáneamente. La encarcelaron y está juzgada de matar, un crimen. Y puede ir a prisión por eso. Está, entonces la ultra derecha tratando de sacar todo derecho de la mujer de poder decidir si quiere o no tener hijos. Pero cuando nace el hijo, esa misma derecha ya se lava las manos y está en contra de la ley social que podría ayudar a la mujer pobre a criar su hijo. Entonces, protegen el feto y matan el hijo.

Sergio: otro eje que me parece interesante que podamos discutir o abrir es esto que tiene que ver con el Psicoanálisis y la política. Como decía Juan Carlos, por las amenazas históricas que ella (Marie Langer) ha tenido durante la década del ‘50 y ‘60 su actividad política estuvo por 
fuera de la institución. Pero tenía relación con algunas feministas y alguna relación con Pichón Riviere también en ciertas colectas o actividades de apoyo a los españoles. Ya en la década del '70 se empiezan a dar los momentos de escisión de la APA y de su actividad militante explícita. No sé si queréis contar un poco...

Juan Carlos: Bueno, primero que en la década del ‘69, en esa época, Marie tenía algunos pacientes en análisis. Esos pacientes eran José Bleger, Armando Bauleo, Tato Pavlovsky. Primero que eran todos varones, y en realidad, yo no sé si iban a analizarse con Mimi, o iban a bajarle línea (risas). La historia es que éramos todos muchachos, yo supervisaba con Mimí, ellos se analizaban. Entonces jugábamos a que nosotros estábamos avivándola, las cuestiones políticas que estaban dándose en el momento. Y desde el diván, estos genios, que eran mis amigos, creían que iban convenciéndola. Ella escuchaba con una sabiduría maravillosa. Porque por supuesto, sabía mucho más desde mucho antes. No obstante eso, cuando se produce el grupo Plataforma y la escisión de la APA, donde Mimí tenía un enorme poder, no se condice con el poder que ella tenía en Plataforma. Porque de APA había sido fundadora y presidente y ella ponía presidentes. En Plataforma no, quienes tenían el poder eran otros. Ella estaba y participaba, lo cual era importante porque piensen que era un grupo donde había miembros de la Asociación, miembros didactas, miembros adherentes y candidatos. Entonces estaba toda la cúpula representada en ese grupo, Plataforma. Pero ella no tuvo para nada un liderazgo, ella acompañó. Ella estaba y acompañaba. Quienes realmente ejercían el poder y lo tenían eran Gregorio Barembilt, Miguel Matrajt, Rafael Paz, y un poco Tato también. Eran los que tenían más compromiso político. Y Armando Bauleo y Hernán Kesselman en realidad fueron los fundadores de Plataforma.

Nancy: Plataforma fue un movimiento internacional. En los congresos de la IPA, primero en Roma en el '71 y después en Viena en el '72 o '73 no recuerdo bien. Con todos los movimientos en Europa, en Estados Unidos y en América Latina y muchas inquietudes entre los candidatos y aún entre los analistas, se formaba un contra-congreso durante el congreso de la IPA. Pero fueron los argentinos y solo los argentinos que, regresando a su lugar, se separaban de su instituto Psicoanalítico. En el congreso en Viena, Mimí dio su última presentación dentro de la IPA. Su presentación se llamaba "Psicoanálisis y/o revolución social", dentro de la IPA. Antes de eso, cuando ella iba a hacer presentaciones en la IPA, ella cuenta como Klein misma y Hannah Segal la prepararon porque ella fue una de las pocas Kleinianas que se admiten para presentar dentro de la IPA. Entonces siempre la prepararon, cómo iba a hablar, cómo iba a presentarse, etc. Cuando ella presentó esto de Revolución social, advirtiendo a los psicoanalistas (esto fue a comienzos del 73 creo) que no todos los psicoanalistas después de la revolución cubana salieron de Cuba. Que los chilenos, Paco Allende, que no salieron, que se dedicaron a integrar Psicoanálisis con la Revolución Social. Ellos sabían que esa fue su despedida, y fue muy rechazada por Hannah Segal en ese momento, porque era una violación total del Psicoanálisis que ellos practicaban. Así que eso fue, yo creo que una posición muy valiente de ella. De animarse a hacer eso y desafiar a sus colegas internacionales.

Sergio: Bueno para ir terminando, te quería preguntar si vos sabes de una curiosidad, porque ella se analiza allá en Austria con Sterba. Si ella, acá en Argentina, hace algún análisis?

Juan Carlos: ella se analiza en Viena con Richard Sterba, que era paciente de Freud y acá con Cárcano.

Sergio: Vos tradujiste el libro "Maternidad y sexo". Quería saber qué repercusión tuvo en Estados Unidos, si ha sido leído, si se ha reeditado, por qué medios ha circulado.

Nancy: si, pero bueno yo no podría decirte la cantidad de libros que se vendieron. Pero sí 
se ven referencias al libro; pero el impacto principal dentro de todo lo que se publica allá, no.

Sergio: y en el medio académico?

Nancy: y en los medios académicos allá, salvo algunas universidades, no se ocupa mucho del Psicoanálisis, del Psicoanálisis Clínico. En las Humanidades, en la sociología digamos que sí se ocupan más de Psicoanálisis que en las facultades de Psicología.

Sergio: lo último para Juan Carlos, si podemos ver un poquito sobre este momento de ruptura, para ver la relación con Bleger. Porque yo leí y estaban esperando que Bleger rompa, y bueno no llegó. Si podes contarnos algo de eso.

Juan Carlos: bueno Bleger se analizó con Mimí muchos años. Bueno en esa época seis años eran mucho, cuatro veces por semana. Y Bleger fue, de lo que yo contaba antes, esa incompatibilidad entre Partido Comunista y Psicoanálisis, Bleger fue la última víctima. Porque Bleger era miembro del Partido Comunista y era Psicoanalista. Por lo cual lo echaron del PC y después estuvieron a punto de echarlo de la APA. Eso también le había pasado a Wilhem Reich, fue apartado por los psicoanalistas y también lo echaron del Partido Comunista, ya no era más comunista, entonces, pero (risas), tuvo también,... comentaba sobre la poca diplomacia de Bleger, porque él fue a la Unión Soviética y cuando volvió a la Argentina denunció lo que él veía de la Unión Soviética, el antisemitismo... y eso los comunistas no se lo perdonaron y tuvo muchas consecuencias para él, nefastas... una de ellas es que Bleger era marxista, escribió ese famoso libro marxismo y psicoanálisis, era un psicoanalista muy ortodoxo para la época como se usaba en la época. Como comunista anhelaba ir a Cuba, Cuba era el país revolucionario de América, pero quien manejaba toda la relación de Argentina con Cuba era el partido comunista. El partido comunista decidía quienes iban y quienes no iban y Bleger tenía prohibido ir a Cuba, a pesar que, eso sí gracias a nosotros, apenas triunfó la Revolución se hizo la primera carrera de Psicología y nosotros llevamos psicología de la conducta y el libro de Bleger se convirtió en la biblia de la carrera de psicología de La Habana, de Santa Clara y de Santiago. Entonces, a pesar de que la obra de Bleger estaba como bibliografía fundamental, él no podía ir a Cuba por esto. Y entonces nosotros hicimos toda una serie de influencias, nos movimos para que Bleger pudiera ir a Cuba, con tal mala suerte que cuando por fin le llegó la posibilidad, la Visa para viajar a Cuba, tuvo un infarto y se murió a los 49 años. Creo que se murió desgarrado por este tironeo entre psicología, política y psicoanálisis, sin duda fue una figura fundamental del desembarco del psicoanálisis en la Universidad, en la Facultad de Psicología de Buenos Aires.

Sergio: cuando Mimí se exilia, se va a Méjico, empieza a tener una relación muy interesante con Nicaragua, ¿querés contarnos un poco esa experiencia?

Nancy: Bueno, al revés de Bleger, Mimí tuvo una gran suerte, en la última etapa de su vida encontró como integrar todas las pasiones de su vida. Y cuando la conocí ya había estado exiliada en Méjico militando en un grupo de solidaridad con refugiados de las dictaduras de América Latina y de los refugiados que llegaron de El Salvador, Guatemala, de Nicaragua. En Nicaragua había una revolución sandinista luchando en contra de Somoza y llegaron algunos soldados heridos, sufriendo trastornos psicológicos de tantas pérdidas y por haber estado encarcelados por Somoza, etc. Y eran centroamericanos que no habían tenido ninguna historia... pero ninguno de sus contactos llegaba a pedir ayuda a Mimí o a algunas colegas argentinas-mejicanas, para encontrar ayuda con el psicoanálisis. Allí empezaron a practicar, a salir de la práctica psicoanalítica basada en la neutralidad, empezaron a practicar una técnica no neutral. Y la manera de poder ayudar a los nicaragüenses es que ellos consideran la historia de ellos mismos como exiliados de una dictadura, la Argentina. Y allí hicieron contacto con nicaragüenses, se quedaron en Méjico 
un tiempito y después regresaron a la revolución. Y después de esa experiencia y el triunfo de la revolución sandinista, el encargado de desarrollar un sistema de salud gratis para todo el país se conectó con los argentinos, inclusive a Mimí en Méjico pidiendo que ellos empezaran a colaborar en el desarrollo de un sistema de salud mental que seguía a una alineación de cada parte de la atención medica que se estaba desarrollando en Nicaragua. Y para mí esto es la cosa más interesante, porque llegamos a la historia intelectual de cómo se combina el marxismo y el psicoanálisis. Mimí, creo que es la única persona con sus colegas en la historia que logró eso en la práctica en un país chiquito, pobre, traumatizado, oprimido, y era una cosa que le daba una alegría, y la posibilidad de integrar todo en la última etapa de su vida; tenia muchísima suerte y ella lo sabía, siempre decía, es como que ganaron los republicanos en la guerra civil; finalmente yo puedo participar. Entonces cuando la conocí estaba muy metida en eso, y yo fui a las reuniones de los equipos internacionalistas de trabajadores de salud mental Méjico-Nicaragua; había, no sé cuanto, pongamos diez, doce personas, se juntaron cada lunes en la casa de Mimí en México, coordinaron el trabajo, y una vez por mes, por diez días, fueron de a dos a trabajar en Nicaragua y tuve la gran suerte de acompañarla a ella y a Ignacio Maldonado otro coordinador Méjico-Argentino, exiliado en Méjico que sigue viviendo en Méjico. Y fui con ellos para observar como trabajaban allá. Y es un trabajo muy, muy interesante, muy lindo, la primera vez que podía practicar psicoanálisis comprometido con la función social apoyado por el gobierno. Cosa que casi no se imagina, increíble. Y me daba mucha satisfacción, por que formaron diferentes equipos, grupos, prácticas, uno fue de tratamiento en grupo, personas que sufrían de trastornos semejantes, para ellos muy interesante; fue una mujer que podía asistir al grupo psicoterapéutico, y después ir a la asociación de mujeres sandinistas, donde había apoyo para la mujer y la posibilidad de repensarse integrándose en actividades a favor del cambio social, la lucha para la reivindicaciones de la mujer, era increíble. Entonces había muchas diferentes experiencias de Mimí y Nacho, y ver como llegando de país muy como se dice... europeizado... (Risas...)... yo he conocido muchos argentinos en los ángeles que me dicen, "mirá, no somos indios, no llevamos las plumas, somos gente bien”. (Risas). Pero Mimí y Nacho viajando desde Argentina, trabajando en un país muy humilde, de gente de grupos étnicos, o mezclados, mestizos o indios, con una sensibilidad, una capacidad de relacionarse, de desarrollar la confianza, por parte de ellos, que no tenían experiencia con psicoterapia, no sabían de que se trataba; pero Mimí y Nacho, tenían la capacidad de hacerle sentir tan cómodos y trabajaban en muchos frente, pero el punto que quiero enfatizar ahora, es tanto la experiencia en sí que es única en la historia y ella que estaba con una pasión increíble con ese trabajo. La primera vez que le conocí personalmente, estaba en la universidad juntando fondos para ese trabajo, y a veces también viajaba a Europa, para hablar con colegas allá, para juntar plata, para poder seguir trabajando en Nicaragua. Le fascinaba, le apasionaba y tenía mucha suerte de vivir la última parte de su vida haciendo eso. Y para mí fue un privilegio porque integraba también mi militancia con su militancia

Juan Carlos: Ese fue un acierto, tuvo suerte y logró realizar el sueño de toda su vida, final de su vida, antes yo dije que Bleger justamente fue lo opuesto, el siempre quería ir a Cuba y murió sin poder ir a Cuba; entonces Mimí tampoco podía ir a Cuba, no tanto porque en Cuba tuviera problemas, sino porque el partido comunista argentino era muy dogmático y tenía todavía muchos reparos. Entonces nosotros estábamos viviendo en Cuba y dijimos bueno, si tenés tantas ganas de venir a Cuba, vení de turista, que eso sí se podía. Y entonces vino de turista. Claro, no fue un turismo inocente, porque ella vino de turista, llegó a Cuba y nosotros le presentamos a nuestros amigos; y era muy impresionante como ella iba seduciendo y conquistando, 
pero de una manera, con un estilo discreto. Tenía un" charme", un glamour, había algo, como una especie de aureola, que transmitía encanto. Y entonces, ya a partir de ahí el segundo viaje no fue como turista, sino fue como invitada oficial por el gobierno y a raíz de eso se había organizado un encuentro de intelectuales, por la soberanía de los pueblos de América, en la Habana ,y donde por primera vez además de los escritores, porque estaba Chico Buarque de Hollanda, Mario Benedetti, Eduardo Galeano, Gabriel García Márquez, los grandes escritores y artistas, Julio Cortázar... Pero ese año había muerto Julio Cortázar, entonces el lugar de Julio Cortázar estaba vacío, y la eligieron a ella para ocupar ese lugar en el Comité de Intelectuales; era la primera vez que se incorporaban dos sectores que siempre habían estado como en disputa, que eran la Teología de la Liberación, con la invitación de Frei Betto y el Psicoanálisis, con la invitación a Mimí.

El encuentro entre Fidel Castro y Mimí es parte de esto, de la conclusión, fue un contacto muy conmovedor, muy emocionante, yo tuve el privilegio de presentarlos, pero además tuve la sensación de estar frente a dos animales, que como en la selva se huelen y se reconocen, con una capacidad de seducción mutua, me sentía como en una escena primaria. (Risas y aplausos) ¿Qué hacían ellos dos? Ignorándome totalmente. (Aplausos)

Silvia Grande: Si les parece abrimos justamente el diálogo...

Participante: quería preguntarte, porque tengo entendido que en Nicaragua trabaja con los niños que Somoza había adiestrado para la guerra, en momentos en que, hoy los niños son utilizados para exterminio, como en Irak, en Siria y en Palestina; donde el objetivo del medio es ir diluyendo a los niños y a los jóvenes, y también en Venezuela por parte de la derecha... quería preguntarte, porque tengo referencia que ella trabajó mucho con los niños que habían logrado rescatar de las manos del somozismo, que eran utilizados para destruir al pueblo nicaragüense, si de eso tenés información, porque nos serviría mucho.

Juan Carlos: No, mirá, yo estuve en Nicaragua, en la época de la guerra, estuve antes del triunfo de la revolución, antes de la llegada de los sandinistas a Nicaragua, llegamos a Nicaragua seis meses antes del triunfo de la Revolución, y estuvimos durante el triunfo y después. Fue a raíz de los contactos que nosotros hicimos justamente con el Ministerio Público de Salud, que se armó una vez que triunfó la Revolución, el grupo de Salud Mental...pero que trabajaran con niños, no; yo sí recuerdo que había chicos somocistas, y había también chicos sandinistas, en el frente donde yo estaba, había cosas llenas de contradicciones, pero había chicos que estaban con los sandinistas, chicos de 8, 9, 10 años, que tiraban granadas, cometían atentados contra la guardia nacional... si, sí, la guerra es terrible, para los chicos es una situación terrible: o los matan, o los convierten en asesinos de todas formas.

Participante: Primero que nada agradezco a Nancy primero, a Juan Carlos y, a Sergio, por el espacio, muy interesante y las preguntas; y yendo al grano con una pregunta que me gustaría abrir, especialmente a la historiadora y luego a Juan Carlos. ¿Cuál era? ¿Cómo Mimí ve la figura de Evita en la política del peronismo argentino, y después, cuál es la distancia que toma respecto de Perón en el '74?

Juan Carlos: Eh, yo te voy a decir una cosa, mirá, resulta que en un trabajo que yo escribí sobre Mimí, cuento como ella cuando Evita murió, hizo la cola interminable, la cola con la lluvia, esa cola interminable... besó el cajón de Evita y publiqué eso... cuando yo publiqué eso, los hijos que son unos gorilas terribles, me increparon duramente, porque su madre nunca había sido peronista. Entonces yo fui y agarré el texto de Mimí, donde ella cuenta eso, y les dije, lo que pasa que ustedes nunca leyeron a Marie Langer donde cuenta esa experiencia. 
Nancy: Bueno, es uno de los puntos donde coincidimos nosotras, ella y yo. Yo creo que ella trató de entender el impacto sobre el pueblo Argentino, de la figura de Evita, o de lo que sentía la burguesía de la clase media argentina hacia Evita. Ella escribió ese trabajo sobre un "mito del niño asado". Entonces ella trató de entender la agresión social hacia Evita, y yo también cuando hice mi tesis de doctorado; yo me mantenía desde un punto de vista de una crítica del patriarcado, los límites y las cosas positivas que ella representaba en el contexto de Argentina. Entonces yo creo que su posición hacia Evita era tratar de entender lo complejo que fue; no era peronista sino trató de entender la complejidad del peronismo, y de entender lo de Evita dentro de los patrones patriarcales... y el miedo de la mujer, el odio hacia la mujer, la aversión hacia la mujer y proyectado sobre la mujer, el miedo de la mujer... y de una mujer fuerte.

Sergio: quería agregar que también ella valora las conquistas del peronismo en relación a la precariedad, de la población, y ella misma se expone como en situaciones de precariedad porque además, ella puede autentificar su título de médica recién en el '59. Estuvo muchos años en una suerte de precariedad, y en función de esta idea de precariedad es que ubica al peronismo como un gobierno que había trabajado y conquistado situaciones para los sectores más vulnerados.

Juan Carlos: Eso es interesante, sabes que es interesante esa trayectoria, durante la época del peronismo, del primer peronismo, que coincide con el auge de la Asociación Psicoanalítica Argentina donde había un comisario político. El peronismo no lo proscribió, a pesar de que el desarrollo psicoanalítico argentino era en general de clase media acomodada, anti, gorila, no lo proscribió, ni tuvo ninguna actitud de represión con respecto al psicoanálisis; pero impusieron un comisario político que tenía que estar en todas las reuniones de la APA. ¿Y saben qué paso? Pasó una cosa extraordinaria, el señor este terminó analizándose (Risas)

Juan Carlos: Hay otro dato que tal vez es interesante, yo hablé antes de todo el enfrentamiento del partido Comunista y el Psicoanálisis, toda esa puja tremenda que se llevaba a cabo en aquellos años en los que se jugaba también en la Facultad de Psicología, en los años '50, fines de los '50, principios de los '60. ¿Cómo terminó eso? Terminó en que, los líderes del Partido Comunista, que eran Jorge...(inaudible), Caparrós, el padre de... (inaudible), Caparrós y Gervasio Paz, terminaron todos analizándose con Mimí, así que esa oposición férrea de los Psiquiatras Comunistas al Psicoanálisis se resolvió, con que, bueno, aceptaron a una psicoanalista que era marxista. Quería completar esto, yo dije mal, porque dije todos terminaron analizándose con Mimí, pero no es cierto, porque resulta que Antonio Caparrós, le pidió análisis a Fernando Ulloa, entonces ella... es muy gracioso esto, yo estudiaba Psicología en esa época, entonces en la facultad, estaban muy de moda los Beatles y los Beatles habían ido al Himalaya, entonces de eso se hablaba muchísimo y empezó a correr la bola en la Facultad, de que Antonio Caparrós se estaba tratando con "un yoga", pero no era que era con un yoga, era con Ulloa.

Participante: (...) si podría explicar un poquito más como fue la experiencia del armado, en este sistema de salud de Nicaragua

Nancy: Bueno, se armó un grupo de personas, unas diez o doce personas, de psicoanalistas, psiquiatras comprometidos con la revolución sandinista y con muchas ganas de hacer, y escuché que se reunían una vez por semana para desarrollar una serie de proyectos, y para tener siempre una coherencia entre los diferentes grupos. Así es que les tocó ir diez días de cada mes para seguir desarrollando los proyectos. Algunos proyectos fueron supervisados por los pocos trabajadores de Salud Mental que había en ese momento en Nicaragua, en condiciones muy primitivas. Era increíble, por ejemplo, hacer una supervisión en una habitación muy chiquita, en un centro donde estábamos parando... sobre dos camitas simples: seis, siete, ocho personas, 
explicándoles, supervisando; trabajando con pediatras de la Universidad de León para enseñarles lo que se llamaban Grupos Balínt, para enseñarles la dimensión transferencial, tanto del pediatra hacia sus pacientes chiquitos y de los pacientes hacia los pediatras. Para mostrarles que no solo era un tratamiento médico, que tenían que estar al tanto de cómo tratar a un chico que estaba muriéndose de cáncer, y entender lo que pasaba al pediatra mismo. O enseñarles que a un chico de un año y medio o dos años no se lo podía tratar como un objeto hablando solo con la madre, que tenían que relacionarse con el chico. O dar clases dentro del ejército Sandinista que en ese momento estaba, luchando en contra de los Contra, financiados y entrenados por mi querido país... y enseñarles que no podían lograr éxito tratando de convencer a un soldado que había estado en el frente y que había sufrido un trauma, que sufría trasfondos de miedo, mucha culpa y no quería regresar al frente, que tenía miedo, que no podia, y con un superyo muy fuerte. Ellos enseñaron que todo el mundo en el conflicto tenía una parte muy buena, dispuesto a hacer lo bueno en este contexto, luchar para la revolución y una parte no tan buena, etc., etc. Tratar de suavizar el tratamiento de los psiquiatras dentro del ejército para practicar con los soldados que tenían problemas psicológicos y generar empatía y que no funcionasen reforzando el súper yo para conseguir que los regresaran al frente.

Y otra cosa es que había muchos movimientos de solidaridad con diferentes sectores de la población: uno fue con los refugiados salvadoreños y guatemaltecos que estaban huyendo hacia Nicaragua por las guerras en sus países. Una cosa que me conmovió mucho es que había una organización de solidaridad con los refugiados y que un grupo de trabajadores de Salud Mental trabajara con los Sandinistas... ese movimiento tenía contacto directo con los refugiados, y el equipo dirigido por Mimí trabajaba con los refugiados, enfatizando la importancia de estar abierto a lo que expresa el refugiado... y generar empatía, capacidad de entenderlo, de estar a su lado, acompañarlo. Enseñando cómo hay que comportarse para que el refugiado se sienta entendido, apoyado... era increíble, una humanidad muy impactante, muy impactante. Bueno y también supervisando en los Hospitales... había un Hospital Psiquiátrico, supervisaban los pocos psiquiatras que había.... tanto Mimí como Maldonado tenían una sensibilidad tan importante. Ellos quisieron producir un panfleto, iban a llamarlo los diez mandamientos del psicoanálisis, las ideas del psicoanálisis explicadas muy simples, que se pueden aplicar en condiciones muy primitivas, con mucha pobreza, es un psicoanálisis sin diván.

Participante: Pensaba en la total vigencia de todas estas figuras que aparecen: el lugar de la mujer, la política y el psicoanálisis, y la intervención social, el lugar del psicoanálisis en las intervenciones sociales, para poder articular esto que decía Silvia de "si se trata de historia vieja o si se trata de una historia contada en el presente”, ¿no?, ¿Qué podemos pensar de esa articulación, entre esta historia tan rica y las situaciones actuales?

Nancy: Bueno, en mi país sufrimos un drama, recientemente, con la elección de Trump, y nos empatamos con ustedes... vengo desarrollando desde hace unos diez, doce años un movimiento dentro del psicoanálisis de gente comprometida con una revolución social o un compromiso social, y hay proyectos en todo el país de psicoanálisis con deseos de trabajar en comunidades diversas, pobres, de negros, de latinos, de inmigrantes; no solamente de demostrar solidaridad, sino de tener proyectos que les presten servicios en salud mental. Como Mimí dijo que en la última parte de su vida podría lograr (intentó) llevar a cabo una militancia dentro del psicoanálisis, de aplicar el psicoanálisis a lo social, y allá -me imagino que acá también, pero te cuento de allá- aún más y más y más; y desde la elección de Trump, hay más y más psicoanalistas y psicólogos que se dan cuenta que lo político es personal, que ahora no hay el lujo de sepa- 
rar las dos cosas... y que si no fuera por una teoría que desarrolla ese principio... lo usan ahora en la práctica porque los pacientes mismos vienen con mucha preocupación, mucho miedo, mucha ansiedad por lo que está pasando y por lo que va a pasar... entonces sí, en la actualidad, es muy importante todo esto.

Participante: yo quería preguntar lo que tiene más que ver con... pero pensaba, hace poco leía una investigadora (no recuerdo el nombre) que recupera una crítica a Mimí, planteaba que si "ella" fue parte de la APA por qué no critico a la APA cuando estaba adentro, cosa que yo no comparto; y además me parece que tiene que ver con que..., a mi la figura de ella me apasiona porque me parece que encarna la lucha política, un poco es lo que Nancy planteaba, pero me quedaba con esto que Sergio decía, "bueno, está su huella en las prácticas"; está bien, pero no está, yo es la primera vez, pertenezco a una generación que es la primera vez que escucha el nombre de Mimí Langer en la Universidad, en la Universidad me refiero a las paredes de la Universidad, no se da en los planes de estudio, la conocí por fuera, de casualidad, y veo que generacionalmente ustedes obviamente que tienen otro acercamiento, y pensaba: qué tiene que ver con ese lugar de invisibilidad en la política, en el psicoanálisis, e incluso en la lucha feminista, y cómo se permite - pensaba mientras leía este autor que no recuerdo- esa crítica que sí se atreven hacerle a Mimí y por ahí, quizás, a los hombres del psicoanálisis no; bueno como para abrir...

Nancy: Si entiendo bien la pregunta, tanto acá como en mi país, los psicoanalistas inmigrantes de Europa llegaron a estos países de culturas muy complicadas; habían llegado de condiciones precarias y de represión; cualquiera decía en mi país que el macartismo estaba reflejado en el mundo intelectual y profesional y no era algo fácil criticar el gobierno, la cultura hegemónica, etc.; y Mimí dice que llegando acá tanto ella como los otros inmigrantes preferían quedarse quietos y militar dentro del psicoanálisis para desarrollarlo, porque el ambiente peronista era muy antipático frente a los patrones europeos, era nacionalista y antiimperialista. Ellos se sentían inseguros, no podían predecir lo que iba a pasar y estaban recién llegados tratando de ubicarse, esperando quedarse; no se animaban a salir a la luz, a ser muy de la izquierda. Separaban su vida, si ella por ejemplo quería hacer algo apoyando el movimiento, lo hacía muy suavecito, no hablaba mucho en la APA de eso. Lo hacía aparte. Entonces hacía cosas... hasta que no podía más...ya llegando a fines de los 60 , cuando todo estalló acá, ahí sí que entonces se animó a salir a la luz con toda su política extremista.

Iris Valles: Bueno me parece que este acontecimiento de la Revista llega además en un momento Institucional muy especial para nosotros. Ya hemos escuchado hacer muchos chistes con esto de venir a estar en el fondo, y a mí no me desagrada, es más, me lleva un poco a la época de Humanidades y Artes, no necesitábamos ni manteles, ni alfombras, ni todo eso. Y digo un momento muy especial porque en síntesis, lo importante hoy es centrarse en la transmisión en acto que fue este encuentro. Una de las características principales es esa ponderación que nos atraviesa como institución donde pareciera que hay posiciones teóricas que en sus fundamentos permiten la neutralidad. Ese creo que es uno de los principales problemas, la contracara de esto entonces es que es muy fácil sostener discursos progresistas, ideológicos detrás de reivindicaciones sectoriales que hacen que especialmente nosotros los docentes no nos veamos llevados a dar cuenta de los fundamentos de la transmisión lo que es nuestra obligación a instalar en esta institución. Estamos en un momento muy crítico, entonces ha sido un lujo tener esto hoy, no? Porque, yo pensaba que bueno, porque siempre con Silvia, y con, bueno ahora que hemos recuperado a Claudio luego de sus años de Italiano, muchos de los acá presente, cada vez que historizamos parece que comenzamos con la interhospitalaria y la interhospitalaria es esto que 
hoy pasó acá adelante. Nosotros no hubiéramos existido nunca como colectivo, y aquí nombro no solo el posgrado sino que el posgrado cae en una red de otros colectivos, si algo de eso no nos hubiera sido transmitido, sino hubiéramos estado ocupados en buscar esas raíces, no para el pasado, sino porque siempre estuvimos convencidos de la potencia de este pensamiento. Un pensamiento que obliga a dar fundamentos y que tiene como insignia, a Fernando, una ética del compromiso, él decía: "vos no vas a ir a trabajar con los pobres, uno trabaja en la pobreza", y ese es otro tipo de compromiso, no hay víctimas, trabajamos con el semejante, apostamos. Entonces creo que tuvo un doble valor la jornada de hoy, para los que han sido cursantes de la carrera o cercano a ella, seguramente les volvió mucho todo lo que hemos compartido a veces con Juan Carlos que responde tan prontamente a los pedidos y tan generosamente; lamentablemente esos actos sorprenden, no debería ser tan así pero es así y entonces hay que hacerlo público a esto, acá no hay una cuestión de honorarios... y no porque este mal paga una actividad, digo para poner en primera instancia qué es lo que a ellos también los convoca cuando intentan hacer esta transmisión. Entonces, me parece que hoy se puso en juego esto, no? Como decía, los que han sido cursantes, que fueron alumnos nuestros, muchas veces han escuchado a Juan Carlos o a Fernando Ulloa, hablar acerca de esto, porque Fernando sí nos habló mucho de Marie Langer a nosotros, no solo por los tiempos que vivimos... cuando lo despedimos a Fernando, yo no podía dejar de pensar cuando él hablaba de "por quien doblan las campanas" despidiendo a Marie Langer, entonces digamos que hoy siento que muchas campanas están sonando y no para despedir a alguien, sino para darle la bienvenida a que en las paredes de esta facultad vuelva a resonar algo de esto. Esto tiene mucha más potencia que discusiones técnicas que a veces tenemos. Es toda una metáfora que mientras intentamos dar fundamentos de todo lo que constituye la humanidad que no excluye justamente la sexualidad, estamos ubicados al lado de un congreso de sexología. No digo esto porque tenga algo en contra de ese Congreso, lo pienso más en términos de lo institucional. No por las personas que están acá en ese encuentro (refiriéndose a participantes del congreso), sí eso se propaga, eso se muestra. Esto, lo que hoy hacemos, tiene que estar invisibilizado, por suerte somos poco invisibles porque muchos de ustedes nos acompañan, en realidad, nos acampañamos. Hay muchos de ustedes que no son de la Carrera y son parte del colectivo. No quisiera se cierre esta actividad que inaugura esta revista, y que en realidad creemos posibilita segir este modo participativo, sin reiterar que lo que va a estar en la revista es una construcción colectiva, creo que por eso este es un acto inaugural... para que allí estén nuestras palabras, para que allí esté esta historia. Me parece interesante que invitemos a alguno de los compañeros de las nuevas generaciones que están en el Comité Editorial o ex alumnos de la Carrera que puedan dar la bienvenida a este comienzo de la revista, como verán hay jóvenes también. (Risas)

María Eugenia Fidalgo: Buenos días a todos, en primer lugar, en nombre de Barquitos Pintados Experiencia Rosario, les agradecemos a todos por haber venido y especialmente a Nancy, a Juan Carlos y a Sergio por este encuentro; a todos por ser parte de este primer número de la revista que tiene como título "El malestar hecho cultura, apuestas para un abordaje". Bueno, Iris recién hablaba algo de eso que es lo que hacemos cotidianamente en nuestras prácticas, hacer apuestas en lo que hacemos y recuperando también estas huellas, como hablábamos al principio... a veces los nombres se han invisibilizado pero las huellas atraviesan las prácticas de todos los días y es lo que ponemos en juego en esas apuestas que están movilizadas por el deseo. Así que bueno, muchísimas gracias a todos en nombre del Comité Editorial de la revista. (Aplausos) 
Iris: Bueno, los esperamos a todos en la revista y en los otros lugares en los que estamos como institución. Pasa a ser muy importante poder transitar por la revista, esa es la idea. Muchas gracias a todos, especialmente a nuestros invitados, ha sido un gusto. (Aplausos) 